\title{
Global prevalence of cardiometabolic risk factors in the military population: a systematic review and meta-analysis
}

Fereshteh Baygi ${ }^{1}$, Kimmo Herttua', Olaf Chresten Jensen', Shirin Djalalinia ${ }^{2,3}$, Armita Mahdavi Ghorabi², Hamid Asayesh ${ }^{4}$ and Mostafa Qorbani, ${ }^{5,6^{*}}$

\begin{abstract}
Background: Although there are numerous studies on the global prevalence of cardiometabolic risk factors (CMRFs) in military personnel, the pooled prevalence of CMRFs in this population remains unclear. We aimed to systematically review the literature on the estimation of the global prevalence of CMRFs in the military population.

Methods: We simultaneously searched PubMed and NLM Gateway (for MEDLINE), Institute of Scientific Information (ISI), and SCOPUS with using standard keywords. All papers published up to March 2018 were reviewed. Two independent reviewers assessed papers and extracted the data. Chi-square-based Q test was used to assess the heterogeneity of reported prevalence among studies. The overall prevalence of all CMRFs, including overweight, obesity, high low-density lipoprotein (LDL), high total cholesterol (TC), high triglyceride $(T G)$, low high-density lipoprotein (HDL), hypertension (HTN) and high fasting blood sugar (FBS) was estimated by using the random effects meta-analysis. A total of 37 studies met the eligibility criteria and were included in the meta-analysis.
\end{abstract}

Results: According the random effect meta-analysis, the global pooled prevalence (95\% confidence interval) of MetS, high LDL, high TC, high TG, low HDL and high FBS were 21\% (17-25), 32\% (27-36), 34\% (10-57), 24\% (16-31), 28\% (17-38) and 9\% (5-12), respectively. Moreover, global pooled prevalence of overweight, generalized obesity, abdominal obesity and HTN were estimated to be 35\% (31-39), 14\% (13-16), 29\% (20-39) and 26 (19-34), respectively.

Conclusions: The overall prevalence of some cardio-metabolic risk factors was estimated to be higher in military personnel. Therefore, the necessary actions should be taken to reduce risk of developing cardiovascular diseases.

Systematic review registration number in PROSPERO: CRD42018103345

Keywords: Metabolic syndrome, Obesity, Military personnel, Systematic review

\footnotetext{
* Correspondence: mqorbani1379@gmail.com

${ }^{5}$ Non-communicable Diseases Research Center, Alborz University of Medical Sciences, Karaj, Iran

${ }^{6}$ Endocrinology and Metabolism Research Center, Endocrinology and

Metabolism Clinical Sciences Institute, Tehran University of Medical Sciences,

Tehran, Iran

Full list of author information is available at the end of the article
}

(c) The Author(s). 2020 Open Access This article is distributed under the terms of the Creative Commons Attribution 4.0 International License (http://creativecommons.org/licenses/by/4.0/), which permits unrestricted use, distribution, and reproduction in any medium, provided you give appropriate credit to the original author(s) and the source, provide a link to the Creative Commons license, and indicate if changes were made. The Creative Commons Public Domain Dedication waiver (http://creativecommons.org/publicdomain/zero/1.0/) applies to the data made available in this article, unless otherwise stated. 


\section{Key messages}

- The global prevalence of metabolic syndrome in the military population was estimated to be $21 \%$.

- The overall prevalence of obesity in the military population was estimated to be $14 \%$.

- There was considerable variation in the overall prevalence of cardio-metabolic risk factors was considerable among military personnel.

- The findings suggest that implementing interventions for the control of cardio-metabolic risk factors among military personnel seems necessary.

\section{Background}

The global prevalence of cardiovascular diseases and Metabolic syndrome (MetS) has increased over the last 20 years. The prevalence of Mets in men and women varies from $8 \%$ in India to $24 \%$ in USA, and from $7 \%$ in France to $43 \%$ in Iran, respectively [1]. Studies conducted on subjects over the past 20 years revealed that overweight, obesity, hypertension and hypercholesterolemia are the four leading causes of risk factors with the highest share of cardiovascular diseases [2,3]. Mets is defined as a group of metabolic disorders that can lead to developing cardiovascular diseases, including central obesity, dyslipidemia, type II diabetes mellitus, certain cancers and all-cause mortality [1].

Sociodemographic factors (e.g. age, race and ethnicity), health behaviors (e.g. smoking, physical activity) and neuropsychiatric outcomes (depression, post-traumatic disorders) play a decisive role in the development of Mets [4-6]. Some of these factors are independently associated with military service [7, 8]. Military service personnel work in a unique environment characterized by high risk conditions and high levels of occupational stress [9]. It has been reported that military personnel with their heavy responsibilities are more likely to expose a greater risk of developing cardiovascular risk factors $[10,11]$.

Obesity and MetS have become the main health threat factors in military health system and their alarming incidence is a serious challenge for authorized organizations [12]. A study conducted on a population of military personnel in Iran reported that the prevalence of Mets, overweight and abdominal obesity in this group was estimated to be 11, 48 and $45 \%$, respectively [13]. The prevalence of MetS in Chinese general population (16.5\%) was much lower than that in the military population (35\%) [14]. Obesity has been called as a serious national security threat by military institute in the United States [12]. A study on military personnel in Saudi Arabia revealed that the prevalence rates of overweight, obesity and current smoking were 41,29 and $35 \%$ respectively [15].

There are numerous studies on the global prevalence of cardio metabolic risk factors (CMRFs) among military personnel. It is thus important to obtain an overall estimation on the prevalence of above-mentioned risk factors by synthesizing available studies. To date, the current study is the first meta-analysis conducted on this topic globally. Therefore, this study aimed to systematically review the literature on the estimation of the global pooled prevalence of CMRFs, including overweight, obesity, high low-density lipoprotein (LDL), high total cholesterol (TC), high triglyceride (TG), low highdensity lipoprotein (HDL), hypertension (HTN) and high fasting blood sugar (FBS) in the military population.

\section{Methods}

\section{Identification of relevant studies}

This is a comprehensive systematic review of all available evidences on the prevalence of CMRFs in the military personnel. We developed a systematic review adhering to the PRISMA-P guidelines [16]. All the documents are based on the details of the study protocol. Registration number of current study in PROSPERO is CRD42018103345.

The main root of developing the search strategies is based on the two main components of "cardio metabolic risk factors" and "metabolic syndrome" in military personals. To assess the optimal sensitivity of search for documents, we simultaneously searched PubMed and NLM Gateway (for MEDLINE), Institute of Scientific Information (ISI), and SCOPUS as the main international electronic data sources (Additional file 1).

\section{Inclusion and exclusion criteria}

All available observational studies conducted up to March 2018 c on relevant subjects were included. There was no limitation for the target groups in terms of age and gender and language of published studies. In situation of more than one paper from the one study, the most complete data were considered. We also excluded papers with duplicate citation. Non-peer reviewed articles, conference proceedings and book chapters were considered for more access to relevant data.

\section{Quality assessment and data extraction}

After completing all three steps of data assessment for titles, abstracts and full texts, the full texts of each article selected were retrieved for more detailed analysis. The quality assessment and data extraction were followed a check list recorded citation, publication year, study year, place of study, type of study, population characteristics and methodological criteria (sample size, mean age, type of measure, results of measures and other information).

The whole process of searching for the data extraction and quality assessment was followed independently by two research experts. The kappa statistic for agreement of quality assessment was 0.94 . Probable discrepancies between experts were resolved by discussion. Any disagreements were resolved by consensus by a third person. The quality 
assessment was performed using a validated quality assessment checklist for prevalence studies [17]. This tool comprises 10 items which covers methodological quality of prevalence studies, including sampling method (2 questions), data collection (5 questions) and data analysis (3 questions). Each item can be answered either Yes/No or Unclear/ Not applicable. The overall score for 10 studies was the total score $\geq 6$, considered as acceptable in terms of quality.

\section{Statistical analysis}

The prevalence and 95\% confidence intervals (CI) were used for presenting the results. Chi-square based on $\mathrm{Q}$ test and I square statistics were used to assess the heterogeneity of reported prevalence among the studies. $P<0.05$ was regarded as statistically significant at. Due to severe heterogeneity among studies regarding reported prevalence, the pooled prevalence was estimated using a random-effect meta-analysis proposed by Der-Simonian and Laird. We undertook a meta-regression analysis to assess the effect of study covariates, including the mean age of participants, quality score, type of personnel, and years of publication of reported prevalence. Meta-analysis was performed for risk factors reported in more than four studies. If a study was reported separately the prevalence of CMRFs over a time period, the weighted prevalence for the entire period would calculate and then this value could be considered as an overall prevalence in the meta-analysis. The prevalence of MetS was extracted according to International Diabetes Federation (IDF), World Health Organization (WHO) and National Cholesterol Education Program- Adult Treatment Panel III (ATPIII) criteria. Since most studies had reported MetS by ATP-III criteria, only these studies were included in meta-analysis. To assess the effect of each study on overall prevalence, we performed sensitivity analyses by sequentially removing each study and rerunning the analysis. Statistical analysis was performed using STATA software, V.11.1 (StataCorp LP, College Station, Texas, USA).

\section{Results}

\section{Study selection process}

Figure 1 shows the flowchart of selection of studies for inclusion in the meta-analysis. In total, 2395 papers were identified after initial database search. Of these, 51 fulltext papers were assessed for eligibility. In the next phase, 14 full text papers were excluded and finally 37 studies were eligible for inclusion in this meta-analysis: $[9,13,15,18-51]$.

\section{Study characteristics}

The selected articles were published between 2001 and 2017. Out of 37 studies, 8 contained the prevalence information for navy, 16 for military personnel, 5 for army, 5 for soldier's /warship personnel and 3 for air force staff. Six studies had reported trends in the prevalence of CMRFs over a time period [22, 24, 26, 28, 30, 40], so that their weighted prevalence was considered as an overall prevalence. Among all publications, 15 studies were conducted in the American countries [9, 19, 20, 24-27, 29-32, 36, 38, 41, 51], 13 in Europe [22, 28, 33$35,37,39,40,44,45,48-50]$ and 9 in Asia $[13,15,18$, $21,23,42,43,46,47]$.

\section{Qualitative synthesis}

Table 1 shows the general characteristics of the selected studies for the prevalence of MetS. According to ATPIII criteria, the highest and lowest prevalence rates of MetS were 39 and 9\% in US mariners [31] and French military staffs [49], respectively. The prevalence range of MetS was 3.8-39\% according to the different definition criteria.

Characteristics of the selected studies for the prevalence of overweight, generalized obesity and abdominal obesity are shown in Table 2 . The highest prevalence of overweight (66\%) and obesity (62\%) was reported in Danish seafarers and the US submariners, respectively.

Table 3 shows the characteristics of the selected studies for the prevalence of abnormal lipid profile and other CMRFs. A study carried out by Smoley et al. [41] in the US found the highest prevalence (63\%) of Pre-HTN. The highest and lowest prevalence rates of HTN were observed in the Brazilian military (55.8\%) and the Iranian military (2.6\%), respectively. The highest and lowest prevalence rates of high TG were 50.9\% [9] and 5.0\% [32] for American military personnel.

\section{Meta-analysis}

The results of meta-analysis are shown in Table 4. The total sample size of the studies included in meta-analysis was $n=12,153,936$. The study population consisted of men and women aged 16-66 years. The eligible studies for estimation of the prevalence of MetS, overweight, obesity, high LDL, high TC and HTN were 10, 19, 22, 29, 6 and 13, respectively.

According to random effect meta-analysis, the rates of the global pooled prevalence (95\% confidence interval) of MetS, high LDL, high TC, high TG, low HDL and high FBS were 21\% (17-25), 32\% (27-36), 34\% (10-57), 24\% (16-31), 28\% (17-38) and 9\% (5-12), respectively. Moreover, the rates of the global estimated pooled prevalence of overweight, generalized obesity, abdominal obesity and HTN were 35\% (31-39), 14\% (13-16), 29\% (20-39) and 26\% (19-34), respectively. Figure 2 shows a forest plot of eligible articles for the estimation of MetS prevalence.

\section{Quality assessment}

The quality assessment of the included studies was performed by using a critical appraisal tool for use in 


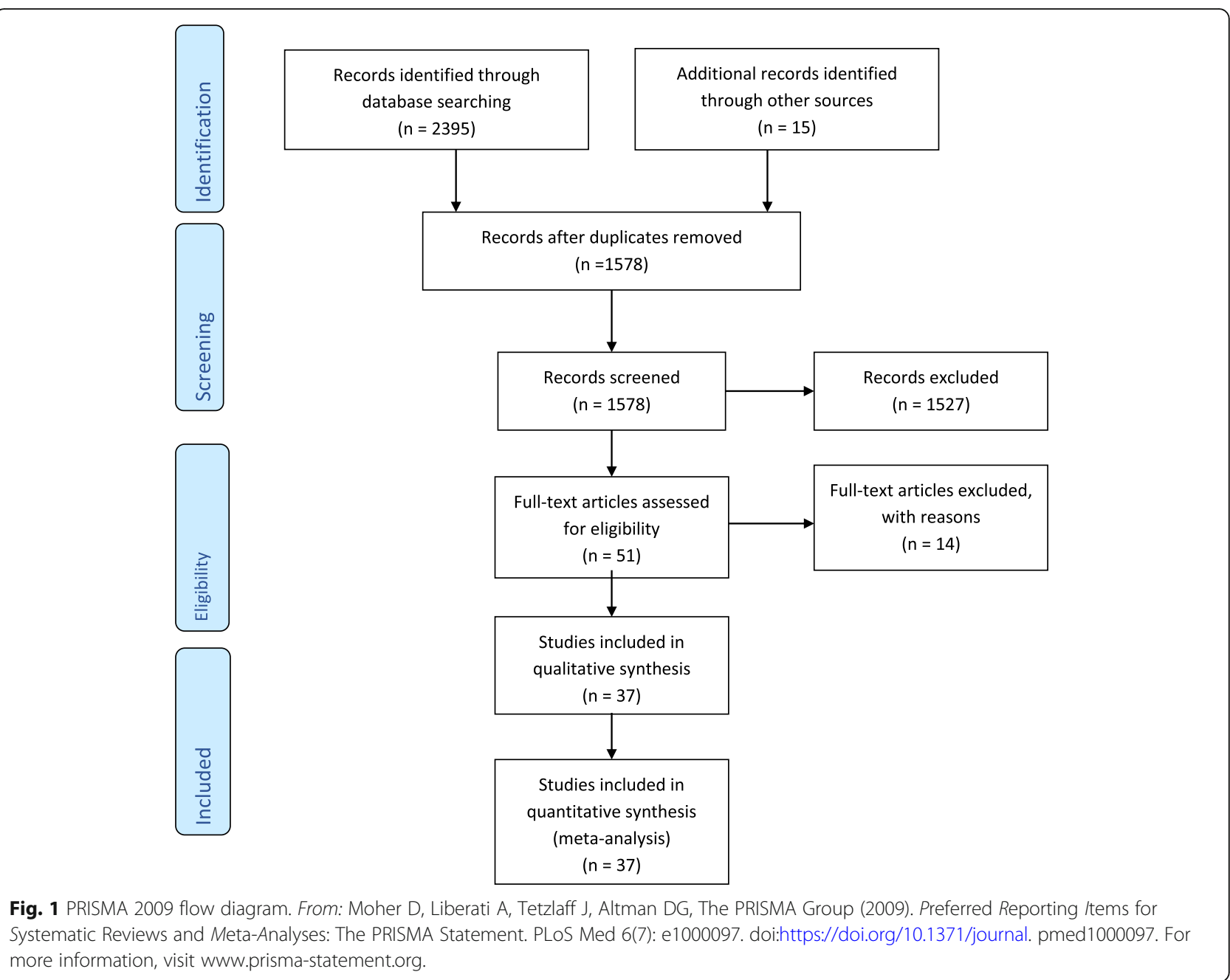

systematic reviews addressing questions of prevalence. Accordingly, all studies had an acceptable quality score (Table 5).

\section{Meta-regression}

Results of meta-regression analysis demonstrated that effect of study characteristics, including the mean age of participant, quality score, type of personnel, and years of publication on reported prevalence was not statistically significant $(p>0.05)$.

\section{Sensitivity analysis}

Sensitivity analyses were performed to assess effect of each individual study on pooled prevalence rates. The results showed that no significant changes in in the pooled prevalence was found in the included studies ( $\mathrm{p}>0.05)$.

\section{Discussion}

To the best of our knowledge, this is the first meta-analysis to estimate the global pooled prevalence of CMRFs in the military population. In the current study, the overall prevalence of MetS was estimated to be $21 \%$ according to ATPIII criteria. The prevalence of Mets was among Iranian male military personnel 11\% [13]. Corresponding prevalence was $35 \%$ in Chinese military population, while it was $17 \%$ in the Chinese general population [14]. The prevalence of Mets was 39\% among Brazilian soldiers [9], whereas it was 15\% among Royal Jordanian Air Force pilots [4]. In a study conducted by Baygi et al. on Iranian seafarers demonstrated that the prevalence of Mets was $15 \%$ which was lower than that (33\%) for urban dwellers of Tehran [21]. The wide variation in these prevalence rates may be due to differences in study samples, age and gender.

In the present study, the estimated prevalence rates of overweight, obesity and abdominal obesity were 35 , 14 and 29\%, respectively. Bin Horaib et al. in their study of 5 military regions of Kingdom of Saudi Arabia among 10,500 active military personnel reported that the proportions of overweight, obesity and abdominal obesity were 41,29 and $42 \%$, respectively [15]. The prevalence rate of overweight was $52 \%$ in the U.S. 


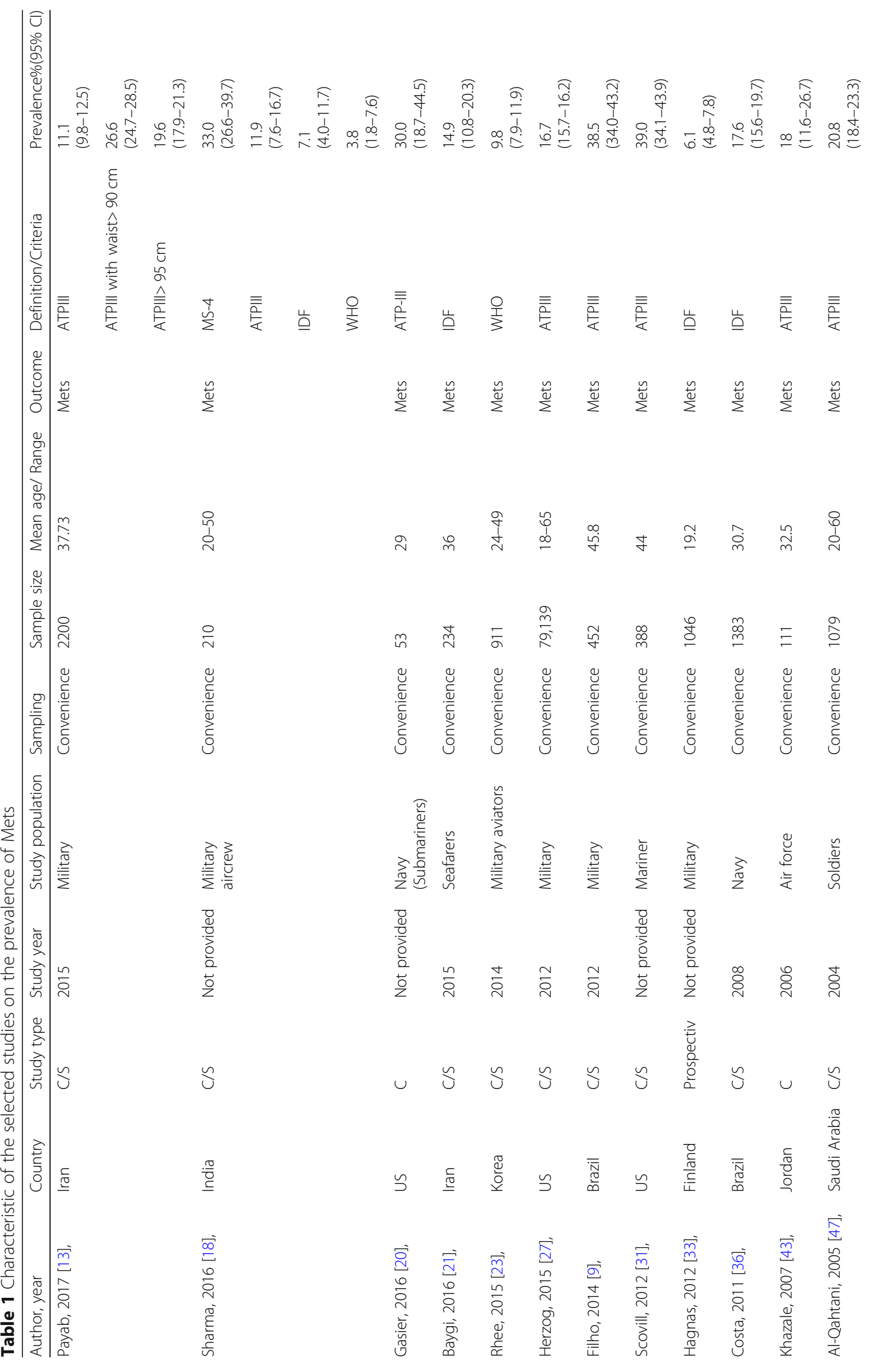


Baygi et al. BMC Endocrine Disorders

(2020) 20:8

Page 6 of 17

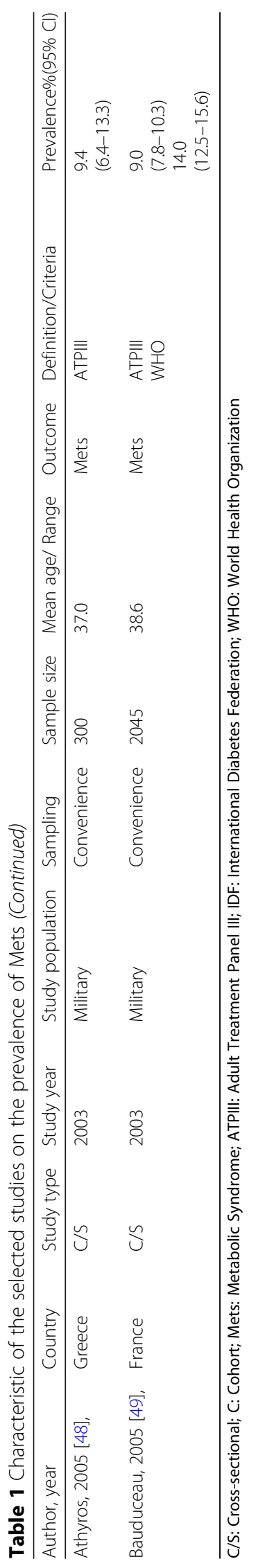


Baygi et al. BMC Endocrine Disorders $\quad$ (2020) 20:8

Page 7 of 17

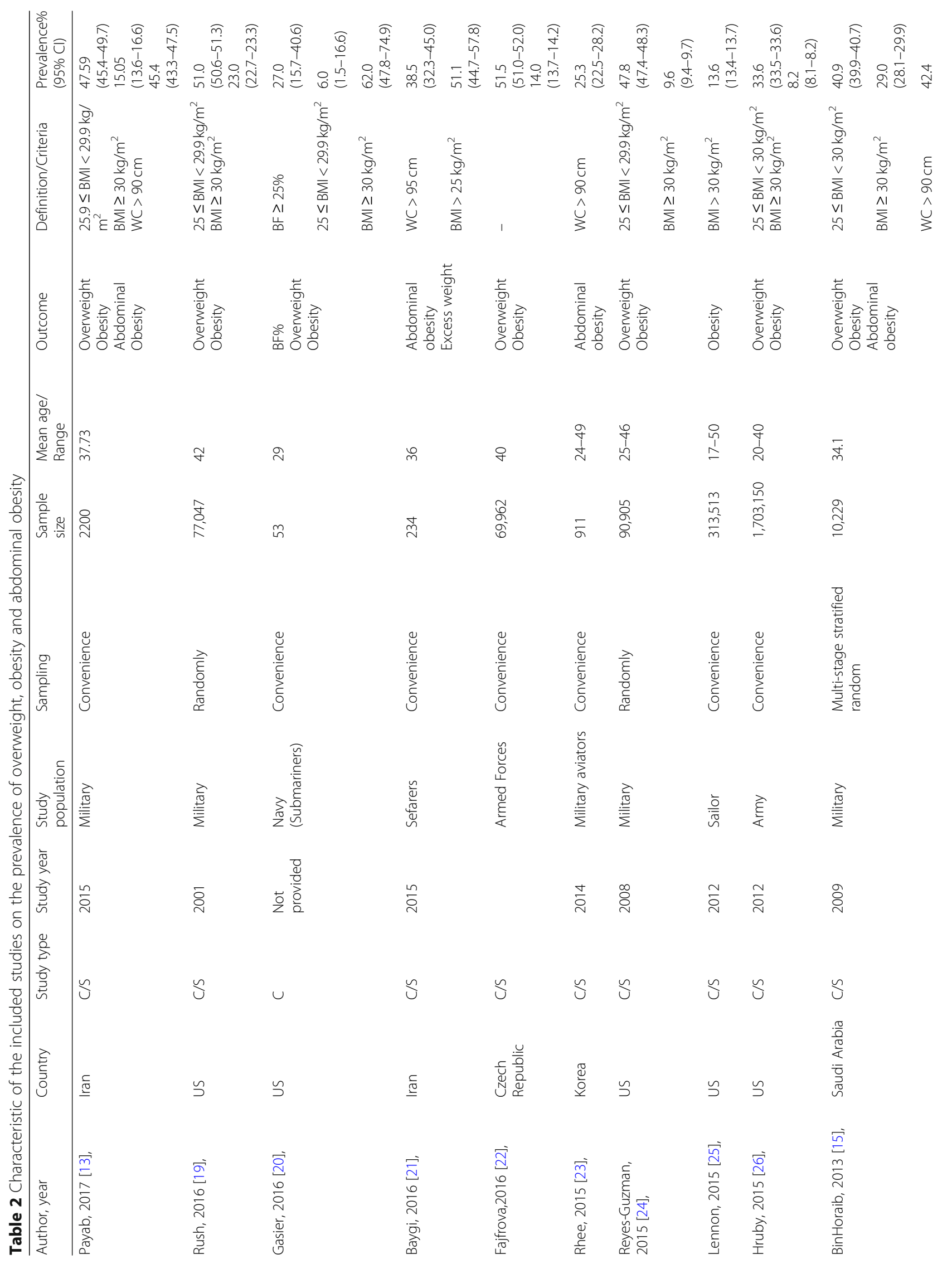




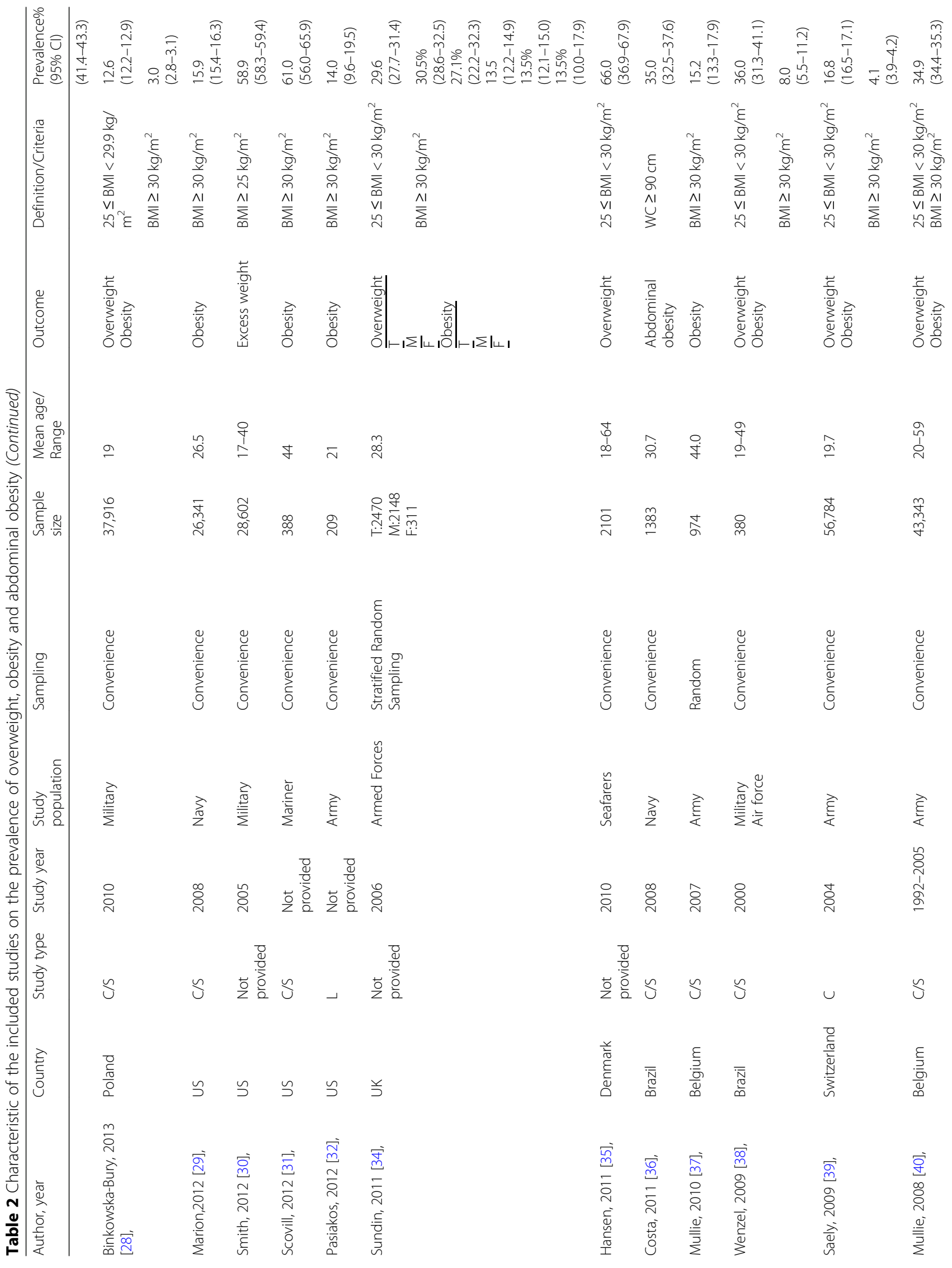


Baygi et al. BMC Endocrine Disorders $\quad$ (2020) 20:8

Page 9 of 17

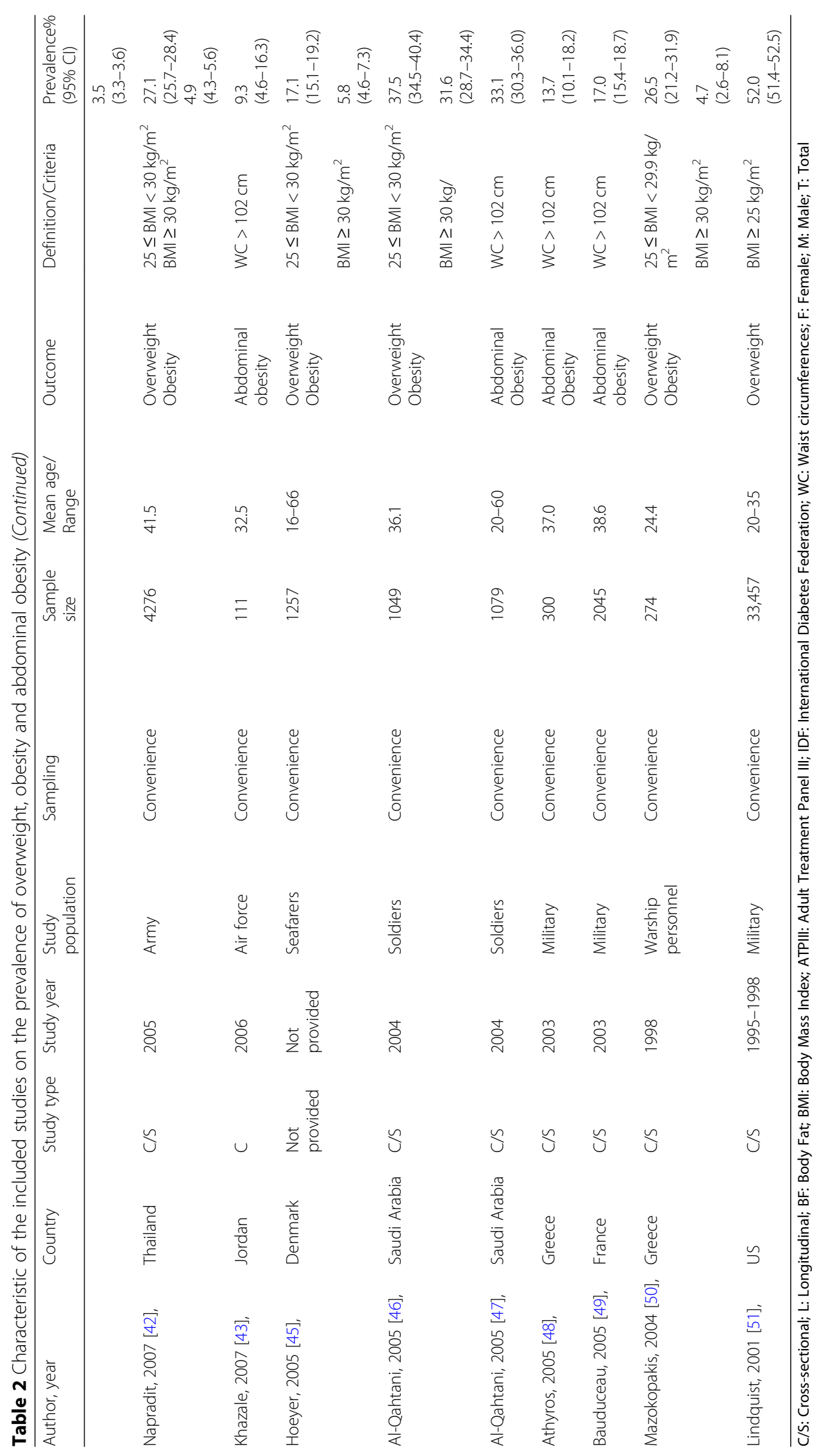




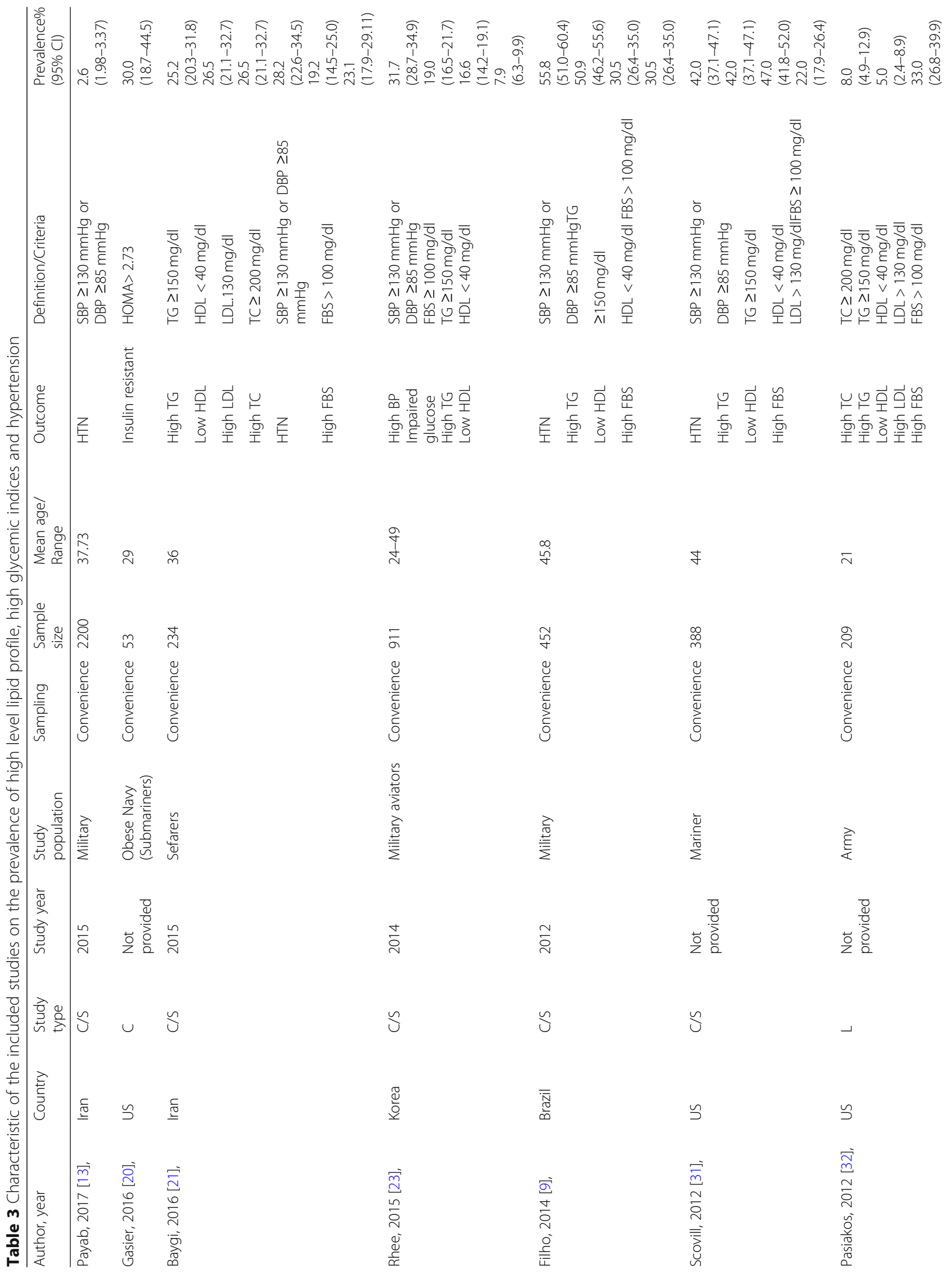




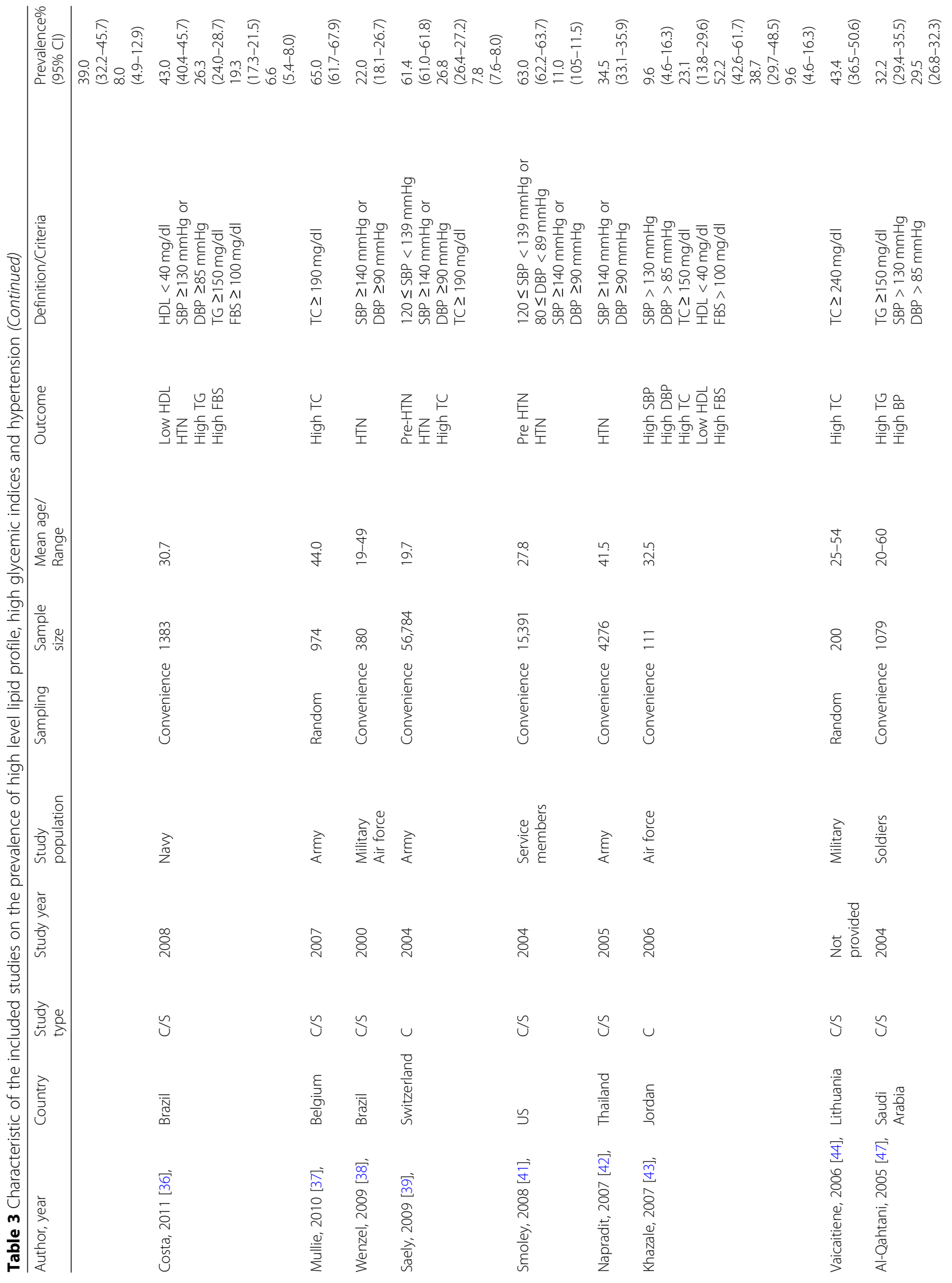




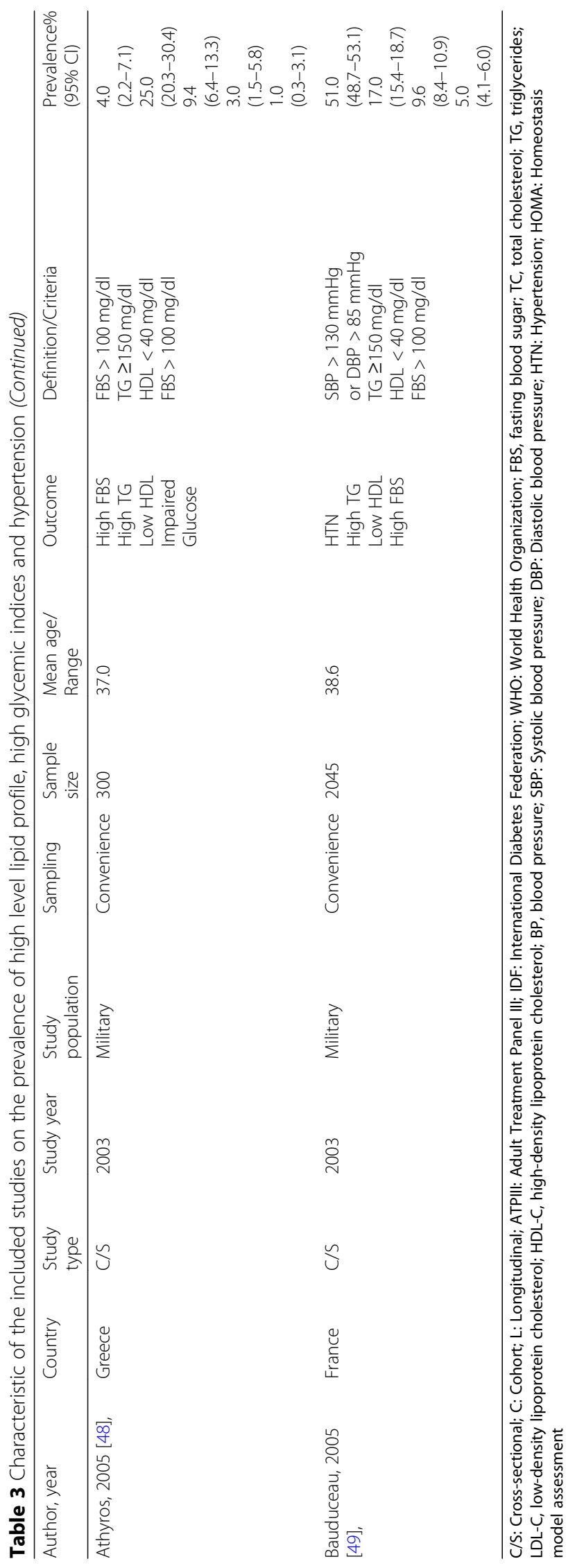


Table 4 The pooled prevalence of cardiometabolic risk factors in Military Population at global level using random effect metaanalysis method

\begin{tabular}{|c|c|c|c|c|c|c|}
\hline Variables & No. of studies & Sample Size & Prevalence (Cl 95\%) & Model & $I^{2}(\%)$ & ${ }^{*} P$-value \\
\hline$\overline{\text { MetS }}$ & 10 & $4,912,369$ & $21(17-25)$ & Random & 97 & $<0.001$ \\
\hline Overweight & 19 & $2,867,867$ & $35(31-39)$ & Random & 99 & $<0.001$ \\
\hline Obesity & 22 & $3,211,654$ & $14(13-16)$ & Random & 99 & $<0.001$ \\
\hline Abdominal obesity & 8 & 17,581 & $29(20-39)$ & Random & 99 & $<0.001$ \\
\hline HTN & 13 & 816,414 & $26(19-34)$ & Random & 99 & $<0.001$ \\
\hline High TG & 9 & 7001 & $24(16-31)$ & Random & 98 & $<0.001$ \\
\hline Low HDL & 9 & 6033 & $28(17-38)$ & Random & 99 & $<0.001$ \\
\hline High LDL & 29 & 157,730 & $32(27-36)$ & Random & 99 & $<0.001$ \\
\hline High TC & 6 & 58,512 & $34(10-57)$ & Random & 99 & $<0.001$ \\
\hline High FBS & 6 & 4436 & $9(5-12)$ & Random & 92 & $<0.001$ \\
\hline
\end{tabular}

*According to $Q$ test (Chi-square test)

navy [51], whereas it was 66\% among Danish seafarers [35]. Using the dissimilar cutoff points and including females in some of the studies may explain differences between the prevalence figures. Because of the nature of their job, military individuals are generally assumed to be healthier. However, our findings showed an alarming trend in the global prevalence rates of overweight and obesity, which might be due to unhealthy diet practice among military personnel [13].

In the present study, the reported prevalence rates of Pre-HTN and HTN were 62 and 26\%, respectively. A study conducted on male subjects in Saudi Arabia showed that the prevalence rate of HTN was $33 \%$, indicating a progressive increase in body fat with age [52]. The results of a National survey conducted in the U.S. demonstrated that the estimated age-adjusted prevalence of HTN was $27 \%$ in men and $30 \%$ in women [53]. The corresponding estimate in general population of Korea was $33 \%$, increased progressively with age from $14 \%$ among $14-24$-year-olds to $71 \%$ among subjects aged 75 years or older [54]. The prevalence rate of HTN in people with regular and intensive physical activity was $13 \%$ lower than that in their non-active peers [55]. Our results showed that the prevalence rate of

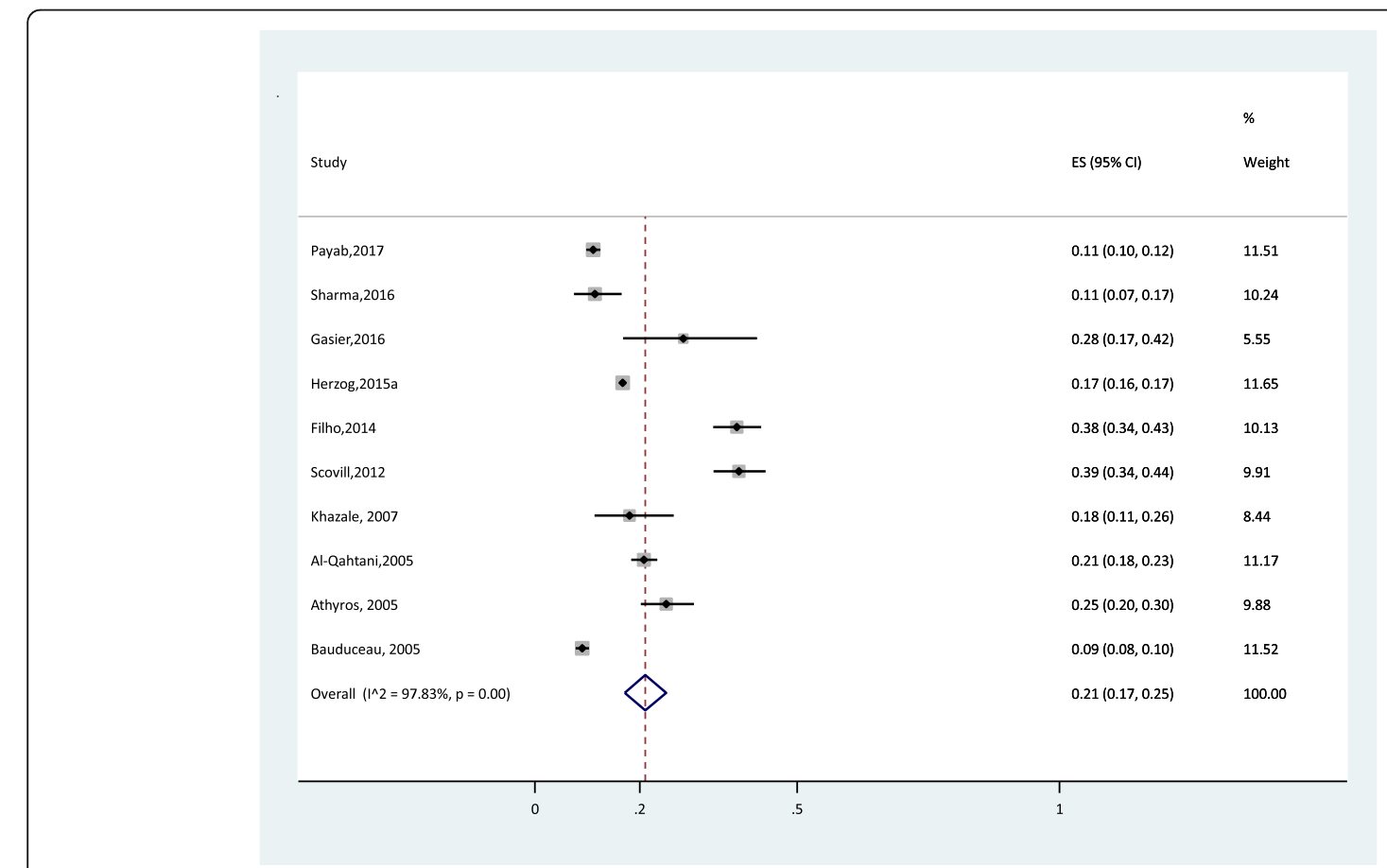

Fig. 2 Forest plot of MetS global prevalence using random-effect model 
Table 5 Quality assessment of the included studies

\begin{tabular}{|c|c|c|c|c|c|c|c|c|c|c|c|}
\hline Study & Total score & Item $_{1}$ & Item $_{2}$ & Item $_{3}$ & Item $_{4}$ & Item $_{5}$ & Item $_{6}$ & Item $_{7}$ & Item $_{8}$ & Item $_{9}$ & Item 10 \\
\hline Payab, 2017 & 7 & $\mathrm{~N}$ & Y & Y & Y & $\mathrm{N}$ & Y & Y & $\mathrm{N}$ & $Y$ & Y \\
\hline Sharma, 2016 & 5 & N & - & Y & Y & N & Y & N & $N$ & Y & Y \\
\hline Rush, 2016 & 6 & N & Y & Y & Y & N & Y & N & $\mathrm{N}$ & Y & Y \\
\hline Gasier, 2016 & 3 & N & $N$ & N & $N$ & N & Y & UC & $N$ & Y & Y \\
\hline Baygi, 2016 & 7 & $\mathrm{~N}$ & Y & Y & Y & NA & Y & Y & $\mathrm{N}$ & Y & Y \\
\hline Fajfrova,2016 & 4 & N & Y & Y & Y & NA & $N$ & Y & $N$ & N & $N$ \\
\hline Rhee, 2015 & 8 & N & Y & Y & Y & NA & Y & Y & Y & Y & Y \\
\hline Reyes-Guzman, 2015 & 7 & N & Y & Y & Y & N & Y & N & Y & Y & Y \\
\hline Lennon, 2015 & 6 & N & Y & Y & Y & NA & Y & N & $\mathrm{N}$ & Y & Y \\
\hline Hruby, 2015 & 7 & N & Y & Y & Y & NA & Y & UC & Y & Y & Y \\
\hline Herzog, 2015 & 7 & N & Y & Y & Y & NA & Y & UC & Y & Y & Y \\
\hline Filho, 2014 & 5 & $\mathrm{~N}$ & $N$ & Y & Y & $\mathrm{N}$ & Y & UC & $N$ & Y & Y \\
\hline BinHoraib, 2013 & 8 & $\mathrm{~N}$ & Y & Y & Y & $\mathrm{N}$ & Y & Y & Y & Y & Y \\
\hline Binkowska-Bury, 2013 & 4 & N & Y & Y & $N$ & NA & Y & UC & Y & $\mathrm{N}$ & $N$ \\
\hline Marion,2012 & 7 & $\mathrm{~N}$ & Y & Y & Y & NA & Y & UC & Y & Y & Y \\
\hline Smith, 2012 & 7 & N & Y & Y & Y & NA & Y & UC & Y & Y & Y \\
\hline Scovill, 2012 & 3 & $\mathrm{~N}$ & Y & Y & $N$ & $\mathrm{~N}$ & Y & UC & $\mathrm{N}$ & $\mathrm{N}$ & $N$ \\
\hline Pasiakos, 2012 & 5 & N & $N$ & Y & Y & $\mathrm{N}$ & Y & UC & Y & $\mathrm{N}$ & Y \\
\hline Hagnas, 2012 & 3 & $\mathrm{~N}$ & Y & Y & $N$ & $\mathrm{~N}$ & $\mathrm{~N}$ & Y & $\mathrm{N}$ & $\mathrm{N}$ & $N$ \\
\hline Sundin, 2011 & 7 & $\mathrm{~N}$ & Y & Y & Y & N & Y & $\mathrm{N}$ & Y & Y & Y \\
\hline Hansen, 2011 & 7 & N & Y & Y & Y & NA & Y & Y & $\mathrm{N}$ & Y & Y \\
\hline Costa, 2011 & 6 & $\mathrm{~N}$ & $N$ & Y & Y & N & Y & $\mathrm{N}$ & Y & Y & Y \\
\hline Mullie, 2010 & 6 & N & $N$ & Y & Y & Y & Y & UC & $\mathrm{N}$ & Y & Y \\
\hline Wenzel, 2009 & 7 & N & $N$ & Y & Y & $N$ & Y & Y & Y & Y & Y \\
\hline Saely, 2009 & 5 & N & Y & Y & N & NA & Y & UC & N & Y & Y \\
\hline Mullie, 2008 & 7 & $\mathrm{~N}$ & Y & Y & Y & $N$ & Y & $\mathrm{N}$ & Y & Y & Y \\
\hline Smoley, 2008 & 8 & N & Y & Y & Y & NA & Y & Y & Y & Y & Y \\
\hline Napradit, 2007 & 7 & $\mathrm{~N}$ & Y & Y & Y & $\mathrm{N}$ & Y & $\mathrm{N}$ & Y & Y & Y \\
\hline Khazale, 2007 & 5 & $\mathrm{~N}$ & Y & N & Y & $\mathrm{N}$ & Y & $\mathrm{N}$ & $\mathrm{N}$ & Y & Y \\
\hline Vaicaitiene, 2006 & 7 & $\mathrm{~N}$ & Y & Y & Y & $\mathrm{N}$ & Y & Y & $\mathrm{N}$ & Y & Y \\
\hline Hoeyer, 2005 & 5 & $\mathrm{~N}$ & $N$ & Y & Y & $\mathrm{N}$ & Y & $\mathrm{N}$ & $N$ & Y & Y \\
\hline Al-Qahtani, 2005 & 6 & $\mathrm{~N}$ & $N$ & Y & $N$ & Y & Y & $\mathrm{N}$ & Y & Y & Y \\
\hline Al-Qahtani, 2005 & 6 & $\mathrm{~N}$ & $N$ & Y & $N$ & Y & Y & $\mathrm{N}$ & Y & Y & Y \\
\hline Athyros, 2005 & 6 & N & Y & Y & Y & N & Y & $\mathrm{N}$ & $\mathrm{N}$ & Y & Y \\
\hline Bauduceau, 2005 & 5 & N & Y & Y & Y & $\mathrm{N}$ & Y & Y & $N$ & N & N \\
\hline Mazokopakis, 2004 & 3 & $\mathrm{~N}$ & $N$ & Y & Y & $\mathrm{N}$ & Y & $\mathrm{N}$ & $\mathrm{N}$ & $\mathrm{N}$ & $\mathrm{N}$ \\
\hline Lindquist, 2001 & 6 & N & Y & Y & Y & Y & Y & $\mathrm{N}$ & Y & $\mathrm{N}$ & $N$ \\
\hline
\end{tabular}

Item ${ }_{1}$ : Was the sample representative of the target population?

Item ${ }_{2}$ : Were study participants recruited an appropriate way?

Item ${ }_{3}$ : Was the sample size adequate?

Item ${ }_{4}$ : Where the study subjects and setting described in detail?

Item 5 : Was the data analysis conducted with sufficient coverage of the identified sample?

Item ${ }_{6}$ : Were objective, standard criteria used for measurement of the condition?

Item 7 : Was the condition measured reliably?

Item ${ }_{8}$ : Was there appropriate statistical analysis?

Item 9 : Are all important confounding factors/subgroups/different identified and accounted for?

Item ${ }_{10}$ : Were subpopulations identified using objective criteria?

Y: Yes, N: No, UC: Unclear, NA: Not applicable 
HTN in military personnel was $26 \%$ that was lower than that in the general population. This is likely explained by a reverse association between intensive physical activity and HTN.

Based on our findings, the estimated prevalence rates of high TG, low HDL, high LDL and high TC were $24,28,32$ and $34 \%$, respectively. The results of a study conducted among 911 Korean military aviators demonstrated that the prevalence rates of elevated TG and reduced HDL were 16.6 and 7.9\%, respectively [23]. The prevalence rates of mentioned figures in the general Korean population were significantly lower than those of their peers in Air Force [56]. A meta-analysis conducted by Tabatabaei et al. in Iranian general population showed that these figures for high TG, low HDL, high LDL and high TC were $41.6,46,35.5$ and $43.9 \%$, respectively [57]. The significant differences between general population and military personnel with respect to lipid profile could be explained by their strict standards for physical activity on a regular basis as which might have positive effects on their overall health status.

In the current study, the overall prevalence rates of high FBS and diabetes were 9 and 5\%, respectively. The global prevalence rare of diabetes for all age groups has been estimated to be $2.8 \%$ in 2000 and $4.4 \%$ in 2030 [58]. The results of a study performed in Greece showed that the prevalence rate of diabetes was $10.6 \%$ in general population and $3.0 \%$ among military staff [48]. This is likely due to higher physical activity levels in the military personnel compared to their peers in the general population. Additionally, nutrition and physical activity of military individuals are strictly controlled for maintaining their healthy body weight which has a positive effect on managing FBS level and preventing Diabetes and other non-communicable diseases and their risk factors.

The limitations of this study are as follows, in most of the included studies, convenience sampling was used to estimate the prevalence which might be decreased generalizibiability of reported prevalence. Moreover, definition of some cardio- metabolic risk factors in the included primary studies was heterogeneous which the pooled prevalence might be limited by the different definitions.

\section{Conclusions}

The overall estimated prevalence of some cardiometabolic risk factors was estimated to be higher in military personnel. Therefore, this study provides strong evidence to the military healthcare providers' and policy makers for devising and implementing feasible interventions in order to control risk factors in this occupation. Moreover, further studies are needed to identify associated risk factors and reveal best predictors of high-risk subpopulation.

\section{Supplementary information}

Supplementary information accompanies this paper at https://doi.org/10. 1186/s12902-020-0489-6.

Additional file $\mathbf{1}$. Search strategy.

\section{Abbreviations}

ATPIII: National Cholesterol Education Program- Adult Treatment Panel III. Cl: Confidence Intervals; CMRFs: Cardiometabolic Risk Factors; FBS: Fasting Blood Sugar; HDL: High-Density Lipoprotein; HTN: Hypertension;

IDF: International Diabetes Federation; ISI: Institute of Scientific Information; LDL: Low-Density Lipoprotein; MetS: Metabolic Syndrome; TC: Total

Cholesterol; TG: Triglyceride; WHO: World Health Organization

\section{Acknowledgments}

Not applicable.

\section{Authors' contribution}

M.Q., F.B., and OCJ conceived and designed the review. F.B., SH.J., and AMG participated in literature review and data extraction. F.B., AMG and H.A., participated in data extraction, interpretation of the results and drafting the manuscript. M. Q participated in data analysis and interpretation of the results. K. H revised the manuscript. All the authors approved the final version of the manuscript submitted for publication.

\section{Funding}

This study was funded by Alborz University of Medical Sciences.

\section{Availability of data and materials}

Data sharing is not applicable to this article as no datasets were generated or analyzed during the current study.

Ethics approval and consent to participate

Not applicable.

Consent for publication

Not applicable.

\section{Competing interests}

The authors declare that they have no competing interest.

\section{Author details}

${ }^{1}$ Center of Maritime Health and Society, Department of Public Health, University of Southern Denmark, Esbjerg, Denmark. ${ }^{2}$ Non-communicable Diseases Research Center, Endocrinology and Metabolism Population Sciences Institute, Tehran University of Medical Sciences, Tehran, Iran. ${ }^{3}$ Deputy of Research and Technology, Ministry of Health and Medical Education, Tehran, Iran. ${ }^{4}$ Department of Medical emergency, Qom University of Medical Sciences, Qom, Iran. ${ }^{5}$ Non-communicable Diseases Research Center, Alborz University of Medical Sciences, Karaj, Iran. ${ }^{6}$ Endocrinology and Metabolism Research Center, Endocrinology and Metabolism Clinical Sciences Institute, Tehran University of Medical Sciences, Tehran, Iran.

Received: 26 April 2019 Accepted: 31 December 2019

Published online: 13 January 2020

\section{References}

1. Eckel RHGS, Zimmet PZ. The metabolic syndrome. Lancet. 2005;365:1415-28.

2. Esteghamati AKO, Mohammad K, Meysamie A, Rashidi A, Kamgar M, Abbasi M, et al. Secular trends of obesity in Iran between 1999 and 2007: National Surveys of risk factors of non-communicable diseases. Metab Syndr Relat Disord. 2010;8(3):209-13.

3. M E. NCD Risk Factor Collaboration. Trends in adult body-mass index in 200 countries from 1975 to 2014: a pooled analysis of 1698 population-based measurement studies with 192 million participants. Lancet. 2016;387(10026): 1377-96.

4. Park YW, Zhu S, Palaniappan L, Heshka S, Carnethon MR, Heymsfiled SB. The metabolic syndrome: Prevalence and associated risk factor findings in the US population from the Third National Health and Nutrition Examination Survey, 1988-1994. Arch Intern Med. 2003;163:427-36. 
5. Heppner PS, Crawford EF, Haji UA, Afari N, Hauger RL, Dashevsky BA, et al. The association of posttraumatic stress disorder and metabolic syndrome: a study of increased health risk in veterans. BMC Med. 2009;7:1.

6. Dunbar JA, Reddy P, Davis-Lameloise N, Philpot B, Laatikainen T, Kilkkinen A, et al. Depression: an important comorbidity with metabolic syndrome in a general population. Diabetes Care. 2008;31(12):2368-73.

7. Richardson LK, Frueh BC, Acierno R. Prevalence estimates of combat-related post-traumatic stress disorder: critical review. Aust N Z J Psychiatry. 2010; 44(1):4-19.

8. Buis LR, Kotagal LV, Porcari CE, Rauch SA, Krein SL, Richardson CR. Physical activity in postdeployment operation Iraqi freedom/operation enduring freedom veterans using Department of Veterans Affairs services. J Rehabil Res Dev. 2011:48(8):901-11.

9. Filho ROJ. The prevalence of metabolic syndrome among soldiers of the military police of Bahia state, Brazil. Am J Mens Health. 2014;8(4): 310-5.

10. Krantz G, Ostergren PO. Double exposure: The combined impact of domestic responsibilities and job strain on common symptoms in employed Swedish women. Eur J Pub Health. 2001;11:413-9.

11. Flynn D, Johnson, J. D., Bailey, C. J., Perry, J. T., Andersen, C. A., Meyer, J. G., \& Cox, N. A. Cardiovascular risk factor screening and follow-up in a military population aged 40 years and older. US Army Med Dept J. 2009;Oct-Dec: 67-71.

12. Shalikashvili JM, \& Shelton, $H$ The new national security threat: Obesity The Washington Post. Retrieved from http://www.washingtonpost.com/wp-dyn/ content/article/2010/04/29/AR2010042903669.html. 2010;April 30.

13. Payab MH-RS, Merati Y, Esteghamati A, Qorbani M, Hematabadi M, Rashidian $\mathrm{H}$, Shirzad N. The prevalence of metabolic syndrome and different obesity phenotype in Iranian male military personnel. Am J Mens Health. 2017;11(2):404-13.

14. Feng YL, Zheng GY, Ling CQ. The investigation of the correlation between metabolic syndrome and Chinese medicine constitution types in senior retired military personnel of the People's Liberation Army. Chin J Integr Med. 2012;18:485-9.

15. Bin Horaib GA-KH, Mishriky M, Selim M, AlNowaiser N, BinSaeed A, Alawad A, Al-Asmari A, AlQumaizi K. Prevalence of obesity among military personnel in Saudi Arabia and associated risk factors. Saudi Med J. 2013;34(4):401-7.

16. Liberati A, Altman DG, Tetzlaff J, Mulrow C, Gøtzsche PC, loannidis JP, et al. The PRISMA Statement for Reporting Systematic Reviews and Meta-Analyses of Studies That Evaluate Health Care Interventions: Explanation and Elaboration. PLoS Med. 2009:6(7).

17. Munn Z, Moola S, Riitano D, Lisy K. The development of a critical appraisal tool for use in systematic reviews addressing questions of prevalence. Int $J$ Health Policy Manag. 2014;3(3):123.

18. Sharma SCA, Singh V. Metabolic syndrome in military aircrew using a candidate definition. Aerosp Med Hum Perform. 2016;87(9):790-4.

19. Rush TLC, Crum-Cianflone NF. Obesity and associated adverse health outcomes among US military members and veterans: findings from the millennium cohort study. Obesity. 2016;24:1582-9.

20. Gasier HGYC, Gaffney-Stomberg E, McAdams DC, Lutz L, McClung JP. Cardiometabolic health in submariners returning from a 3-month patrol. Nutrients. 2016:8:85

21. Baygi F, Jensen OC, Qorbani M, Farshad A, Salehi SA, MohammadiNasrabadi $F$, et al. Prevalence and associated factors of cardio-metabolic risk factors in Iranian seafarers. Int Marit Health. 2016;67(2):59-65.

22. Fajfrová JPV, Psutka J, Husarová M, Krutišová P, Fajfr M. Prevalence of overweight and obesity in professional soldiers of the Czech Army over an 11-year period. Vojnosanit Pregl. 2016;73(5):422-8.

23. Rhee CK, Kim J-Y, Chang E, Park S, Lee W, Kang H. Clinical markers associated with metabolic syndrome among military aviators. Aerosp Med Hum Perform. 2015;86(11):970-5.

24. Reyes-Guzman CMBR, Forman-Hoffman VL, Williams J. Overweight and obesity trends among active duty military personnel A 13-year perspective. Am J Prev Med. 2015:48(2):145-53.

25. Lennon LTOA, McQuade J. Body composition assessment failure rates and obesity in the United States navy. Mil Med. 2015;180(2):141.

26. Hruby AHO, Bulathsinhala L, McKinnon CJ, Montain SJ, Young AJ, Smith TJ. Trends in overweight and obesity in soldiers entering the US Army, 19892012. Obesity. 2015;23:662-70.
27. Herzog CMCS, Eilerman PA, Luce BK. Carnahan CD metabolic syndrome in the military health system based on electronic health data, 2009-2012. Mil Med. 2015;180(1):83.

28. Binkowska-Bury MŻM, Wolan M, Sobolewski M, Januszewicz P, Bolanowski M, Mazur A. Secular trends in BMI changes among the military population between 2000 and 2010 in Poland - a retrospective study. Neuroendocrinol Lett. 2013;34(8):814-20.

29. Marion A, Gregg JC. Physical Readiness and Obesity Among Male U.S. Navy Personnel With Limited Exercise Availability While at Sea. Mil Med. 2012; 177(11):1302.

30. Smith TJMB, Dotson L, Bathalon GP, Funderburk L, White A, Hadden L, Young AJ. Overweight and obesity in military personnel: Sociodemographic predictors. Obesity. 2012;20:1534-8.

31. Scovill SMRT, McCarty DJ. Health characteristics of inland waterway merchant marine captains and pilots. Occup Med. 2012;62:638-41.

32. Pasiakos SMKJ, Lutz LJ, Murphy NE, Margolis LM, Rood JC, Cable SJ, et al. Cardiometabolic risk in US Army recruits and the effects of basic combat training. PLoS One. 2012;7(2):e31222.

33. Hagnas MP, Cederberg H, Mikkola I, Ika"heimo TM, Jokelainen J, Laakso M, et al. Reduction in metabolic syndrome among obese young men is associated with exercise-induced body composition changes during military service. Diabetes Res Clin Pract. 2012;98:312-9.

34. Sundin JFN, Wessely S, Rona RJ. Obesity in the UK armed forces: risk factors. Mil Med. 2011:176(5):507.

35. Hansen $\mathrm{HL}$, Jepsen JR. Obesity continues to be a major health risk for Danish seafarers and fishermen. Int Marit Health. 2011;62(2):98-103.

36. Costa FMV, Alves Lopes TJ, Costa EC. Combination of risk factors for metabolic syndrome in the military personnel of the Brazilian navy. Arq Bras Cardiol. 2011;97(6):485-925.

37. Mullie PCP, Hulens $M$, Vansant G. Distribution of cardiovascular risk factors in Belgian Army men. Arch Environ Occup Health. 2010;65(3):135-9.

38. Wenzel DSJ, Souza SB. Prevalence of arterial hypertension in young military personnel and associated factors. Rev Saúde Pública. 2009;43(5): 789-95.

39. Saely CHRL, Frey F, Leuppi JD LGA, Drexela H, Huber A. Body mass index, blood pressure, and serum cholesterol in young Swiss men: an analysis on 56784 army conscripts. Swiss Med Wkly. 2009:139(35-36):518-24.

40. Mullie PVG, Guelinckx I, Hulens M, Clarys P, Degrave E. Trends in the evolution of BMI in Belgian army men. Public Health Nutr. 2008;12(7):91721.

41. Smoley BASN, Runkle GP. Hypertension in a population of active duty service members. J Am Board Fam Med. 2008;21:504-11.

42. Napradit PPP, Nimit-arnun N, Souvannakitti D, Rangsin R. Prevalence of overweight and obesity in Royal Thai Army Personnel. J Med Assoc Thail. 2007:90(2):335-40

43. Khazale NSHF. Prevalence and characteristics of metabolic syndrome in 111 Royal Jordanian air Force Pilots. Aviat Space Environ Med. 2007 78(10):968-72.

44. Vaicaitiene RCL, Luksiene DI, Margeviciene L. Hypercholesterolemia and smoking habits of Lithuanian military personnel. Mil Med. 2006;171(6):512.

45. Hoeyer JHH. Obesity among Danish seafarers. Int Marit Health. 2005;56(1-4): $48-55$.

46. Al-Qahtani DAIM, Shareef MM. Obesity and cardiovascular risk factors in Saudi adult soldiers. Saudi Med J. 2005:26(8):1260-8.

47. Al-Qahtani DAIM. Prevalence of metabolic syndrome in Saudi adult soldiers. Saudi Med J. 2005:26(9):1360-6.

48. Athyros VGBV, Pehlivanidis AN, Papageorgiou AA, Dionysopoulou SG, Symeonidis AN, Petridis DI, Kapousouzi MI, Satsoglou EA, Mikhailidis DP. The prevalence of the metabolic syndrome in Greece: the MetS-Greece multicentre study. Diabetes Obes Metab. 2005:7:397-405.

49. Bauduceau B, Baigts F, Bordier L, Burnat P, Ceppa F, Dumenil V, et al. Epidemiology of the metabolic syndrome in 2045 French military personnel (EPIMIL study). Diabetes Metab. 2005;31:353-9.

50. Mazokopakis EE, Papadakis JA, Papadomanolaki MG, Vrentzos GE, Ganotakis ES, Lionis CD. Overweight and obesity in Greek warship personnel. Eur J Pub Health. 2004;14(4):395-7.

51. Lindquist $\mathrm{CH}$, Bray RM. Trends in overweight and physical activity among $U$. S. military personnel, 1995-19981. Prev Med. 2001;32:57-65.

52. Kalantan KA, Mohamed AG, Al-Taweel AA, Abdul Ghani HM. Hypertension among attendants of primary health care centers in Al-Qassim region, Saudi Arabia. Saudi Med J. 2001;22:960-3. 
53. Hajjar I, Kotchen TA. Trends in prevalence, awareness, treatment, and control of hypertension in the United States,1988-2000. JAMA. 2003;290 199-206.

54. Jo I, Ahn Y, Lee J, Shin KR, Lee HK, Shin C. Prevalence, awareness, treatment, control and risk factors of hypertension in Korea: the Ansan study. J Hypertens. 2001;19(9):1523-32.

55. Bassett DR Jr, Fitzhugh EC, Crespo CJ, King GA, McLaughlin JE. Physical activity and ethnic differences in hypertension prevalence in the United States. Prev Med. 2002;34(2):179-86.

56. Lim S, Shin H, Song JH, Kwak SH, Kang SM, Won Yoon J, et al. Increasing prevalence of metabolic syndrome in Korea: the Korean National Health and nutrition examination survey for 1998-2007. Diabetes Care. 2011;34(6): $1323-8$.

57. Tabatabaei-Malazy O, Qorbani M, Samavat T, Sharifi F, Larijani B, Fakhrzadeh $H$. Prevalence of dyslipidemia in Iran: A systematic review and meta-analysis study. Int J Prev Med. 2014;5(4):373-93.

58. Wild S, Roglic C, Green A, Sicree R, King H. Global prevalence of diabetes. Diabetes Care. 2004;27:1047-53.

\section{Publisher's Note}

Springer Nature remains neutral with regard to jurisdictional claims in published maps and institutional affiliations.

Ready to submit your research? Choose BMC and benefit from:

- fast, convenient online submission

- thorough peer review by experienced researchers in your field

- rapid publication on acceptance

- support for research data, including large and complex data types

- gold Open Access which fosters wider collaboration and increased citations

- maximum visibility for your research: over $100 \mathrm{M}$ website views per year

At BMC, research is always in progress.

Learn more biomedcentral.com/submissions 